\title{
A CASE STUDY OF "HABITUS" AND "FIELD": THE CHINESE RURAL STUDENTS ON THE UNIVERSITY CAMPUS
}

\author{
Jingyi Dong \\ NTNU, Trondheim, Norway \\ E-mail: jieren987@yahoo.com
}

\begin{abstract}
This research focuses its inquiry on the economic aspect of rural university students' life in China, but the discussion goes beyond the economic field. Massification in the Chinese higher education system has increased the chance for rural youths to receive tertiary education. However, there is rarely sufficient data to record their status quo on the campus. This research intends to fill up the gap by making a comparison between the rural students who are located at different levels in the higher education system. This comparative analysis eventually leads to such findings: Those at the higher extreme of the hierarchy, who have more subsidies, tend to experience more frustration under financial pressure than those at the lower extreme, who are insufficiently funded. Presumably, the former are more directly exposed to ruralurban disparity. While the latter experience less frustration, they are less prepared to impacts from the unfamiliar urban society. The research, eventually going beyond the economic problems, has exposed a process in which the rural youths are victimized by the system that discriminates against the Chinese peasants, in which the higher education system plays a critical role.
\end{abstract}

Key words: higher education, inequality, poverty, rural students.

\section{Introduction}

This research, which illustrates how social institutions incur inequality, focuses its inquiry on the economic aspect of rural students' life on the university campuses in China. It has long been the concern of researchers that in the higher education system rural students are increasingly marginalized (e.g., Liu, 2003; Zhang, 2003). However, in most cases, rural students are lumped together indiscriminately for study. In order to make further distinction and clarification, this study borrows the concept of two extremes from Trow (1973), who envisions inequality in the system of higher education as an aftermath of massification: at one extreme are educational institutions of rich resources and high quality, while at the other extreme are educational institutions of poor resources and low quality (p. 35). Chinese tertiary education institutions are generally divided into 4 classes and further into 8 subclasses. Trow's concept helps reduce this huge and complicated hierarchy into a brief and manageable notion.

As a matter of fact, since the massification was initiated in 1999, the proportion of rural youths on the university campus has increased considerably. However, in this highly stratified system, students' distribution between the two extremes is seriously imbalanced, with most rural students located at the lower extreme, while only a small proportion of them admitted to the higher extreme (Dong, 2004, p. 120, p. 64-69). Does the variation in schools' status and financial resources make a difference to the students? If yes, what are the factors that influence the students? This study therefore raises the following research questions: 
PROBLEMS

OF EDUCATION

IN THE $21^{\text {st }}$ CENTURY

Volume 40,2012

46

\section{How do the rural students respond to variations in financial pressure? And what are the factors that influence their responses?}

In order to answer the above questions, a comparison is made between the rural students who are located at the two extremes of the higher education system, which leads to such findings: Those at the higher extreme, who are more sufficiently funded, tend to experience more frustration under financial pressure than those at the lower extreme, who are insufficiently funded. Further analysis, in the light of Bourdieu's theory, leads to the conclusion that the Chinese universities and colleges play a critical role in the reproduction of the urban-rural segregation system.

\section{Methodology of Research}

\section{General Background of Research}

The general background of this research is as such: 1) China has an urban-rural segregation system, ${ }^{1}$ while higher education is one of the few ways by which rural youths can break through this segregation. 2) Chinese government initiated a massification in higher education in the year 1999, with the students paying high tuition, in order to stimulate domestic consumption as a countermeasure against financial crisis (Kang, 2000). 3) There has been a drastic increase in the number of university and college graduates, ${ }^{2}$ which leads to graduates employment crisis.

Although the study is directed to the systemic level, the setting to present this case is within the geographical boundary of Hebei Province, a place of contrast. Geographically, Hebei encompasses Beijing and Tianjin, two modern metropolises directly administered by the central government. On the other hand, the province has a vast undeveloped rural area with the third largest peasant population in China. With respect to distribution of higher education resources, Beijing and Tianjin boast many universities of high prestige (Subclass 1-3), while Hebei Province hosts those relatively in obscurity (mostly Subclass 4-8).

\section{Data}

The data presented in this research were mainly obtained through semi-structured interviews, which were designed according to principles of grounded theory: It was sufficiently open to "encompass the entirety" of the participants' perspectives. The interviewer's "own ideas, interests, or theoretical understandings were not imposed" on the interviewees (Giske \& Artinian, 2007, p. 69-70). The interview was loosely framed when the interviewer guided the talks with the following hints:

- Family and education background introduction;

- Does the cost of tertiary education pose pressure on family economy?

- What is the proportion of rural students in your class and dormitory? Do you find rural and urban students different?

- Tell something impressive on campus, whether it concerns communication, study or daily life.

The researcher, having been a university teacher for sixteen years in Hebei Province and witnessed the initiation of the massification of higher education, was both the observer and participant. The two parties of the interview came into contact via the researcher's relatives and friends who worked in the circle of higher education, which means that a relation-bond existed before the interview. As a local resident, the researcher had considerable knowledge of Hebei Province. It was therefore possible to quickly find common interests between the two interview 
parties with topics closely related to the background of the rural students, whether it was geography, culture or local specialty. Such features in the researcher-interviewee relationship

PROBLEMS

OF EDUCATION

IN THE $21^{\text {st }}$ CENTURY

Volume 40, 2012 were presumed as icebreaker between strangers and hopefully added authenticity to the data.

The primary inclusion criterion for the selection of interviewees was that the students were from rural areas; most of them were either local residents of Hebei Province or had study experience within the geographical boundary of the province. Balance between genders, university reputation and the economic background of the participants was also taken into consideration. The samples were selected from 10 universities of different levels, including undergraduates and master students. Interviewees were supposed to have some experience on campus. Most of them were therefore selected from above Grade 3 of undergraduate studies. In cases of master degree students, the interviews mainly focused on recollection of their undergraduate life. The number of samples was not decided at the outset. With the interview progressing, similar instances emerged over and over again, which signaled that a category was "saturated" (Glaser \& Strauss, 1999, p. 61). The researcher thus, following the principles of grounded theory, stopped sampling, when 50 students were eventually involved.

Although articles and documents published on the Internet served as one source of information, the most important material took the form of transcripts of audio-recorded interviews, which were conducted between January and March of 2008 via telephone calls. Follow-up email and telephone communication between the two parties provided further materials. As a result of comparison and selection, 13 students were deemed illustrative and included in this study. The interviews of the 13 students resulted in approximately seven hours of recording and over 40 transcribed pages made accordingly. Eventually, information provided by the 13 students was used as resource for the comparative analysis. In order to make it compact and manageable, the information is summarized in two tables, Table 1 and 2. The tables represent the simplified version of a complex phenomenon, which is illustrated in details with extracts from transcripts of tape recording.

Permission was granted by all the interviewees to use the materials in the research on rural students, which would eventually seek publication. Confidentiality was guaranteed by the interviewer.

\section{Analysis}

This study is a comparative analysis that combines grounded theory with discourse analysis. What initiated the study was a general concern about rural students. For quite some time the research lacked a focus. It was not some predetermined research questions that defined the orientation and procedure of data collection. Rather, it was in the process of codification and comparison of the data that the concept of poverty, as well as the students' different responses to poverty, emerged from the muddled and jumbled materials. Accordingly, such research questions were formulated as how rural students responded to financial pressure and why they responded in the way they did.

However, as the research progressed to the phase of data analysis, the study increasingly got entangled in the "complexity of working with extended sequences of talk rather than the brief isolated utterances" (Potter \& Wetherell, 2001, p. 203). And much of the analysis was based on the subjective accounts given by the interviewees, whose language was defined by their unique "interactive context" (Taylor, 2001, p. 7). Consequently, the approach of discourse analysis was combined in the study: First, discourse analysis investigates the contexts of the language, looking for patterns within such larger contexts as "society" or "culture" (Taylor, 2001, p.7). Second, the approach allows detailed analysis of texts. Most important of all, it has the aim of carrying out "critical research" in search of the possibilities for social change (Jørgensen \& Phillips, 2002, p. 66, 2) 
PROBLEMS

OF EDUCATION

IN THE $21^{\text {st }}$ CENTURY Volume 40, 2012

The study departs from looking at the economic aspect of the rural students' life. It will extend to other aspects such as their response to financial pressure, attitudes to study, aspiration for upgrading of their academic qualification, anticipation of future employment, etc. Eventually, by using Bourdieu's concepts such as "field" and "habitus," this research verifies his theory that the educational system is a mechanism to reproduce the existing power relations (Bourdieu \& Passeron, 1990). This comparative analysis per se, however, is insufficient to arrive at any high level generalization, for it is small in scale and heavily relies on data that reflect individuals' subjective feelings. Nevertheless, it suffices the purpose of this study: To interpret a local phenomenon, to record a time of drastic changes, and, hopefully, to provide reference for the on-going discussion on Chinese rural students.

\section{Results of Research}

In Table 1 and 2 shown as follows, by referring to Trow's concept, the higher education system is divided between two "extremes": universities and colleges at the higher extreme versus those at the lower extreme. The students are categorized according to their monthly expenditure and their response to financial pressure. Comparison between the two tables reveals a contradiction: The six students at the higher extreme had easier access to financial aid or had more affluent family condition, but five of them claimed to be under economic pressure. In contrast, the seven students at the lower extreme were less financially aided and were from relatively poor families, but only two or three of them claimed to be under economic pressure. It is this contradiction that justifies further, detailed analysis.

Table 1. Variation in students' economic conditions in relation to variation in students' standings in the higher education system.

\begin{tabular}{|l|c|c|}
\hline \multicolumn{1}{|c|}{ Students } & $\begin{array}{c}\text { High economic standard } \\
\text { (expend 1000 yuan/ month) }\end{array}$ & $\begin{array}{c}\text { Low economic standard } \\
\text { (expend 200-300 yuan/ } \\
\text { month) }\end{array}$ \\
\hline $\begin{array}{l}\text { Lower extreme } \\
\text { (universities affiliated to Hebei Province or } \\
\text { municipalities of the province) }\end{array}$ & Group 1: & $\begin{array}{c}\text { Group 2: } \\
\text { Student A, B, C, D, E, F, G }\end{array}$ \\
\hline $\begin{array}{l}\text { Higher extreme } \\
\text { (universities affiliated to the central govern- } \\
\text { ment, Beijing or Tianjin) }\end{array}$ & $\begin{array}{c}\text { Group 3: } \\
\text { Student H, I }\end{array}$ & $\begin{array}{c}\text { Group 4: } \\
\text { Student J, K, L, M }\end{array}$ \\
\hline
\end{tabular}

Table 2. Variation in students' response to financial pressure in relation to variation in students' standings in the higher education system. ${ }^{3}$

\begin{tabular}{|l|c|c|}
\hline \multicolumn{1}{|c|}{ Students } & Under less financial pressure \\
Universities & $\begin{array}{c}\text { Group 1: } \\
\text { Lower extreme }\end{array}$ & $\begin{array}{c}\text { Under more financial pressure } \\
\text { ner), D, G (state scholarship winner) }\end{array}$ \\
\hline Higher extreme & $\begin{array}{c}\text { Group 3: } \\
\text { Student H, }\end{array}$ & $\begin{array}{c}\text { Group 2: } \\
\text { Student E, F, G }\end{array}$ \\
\hline
\end{tabular}

The interviews identify much similarity among the rural students: Coming from relatively poor families, they are usually highly motivated and diligent in academic study. In contrast to 
the large population of rural children, they are the rare ones (less than $10 \%$ of the rural peers) who finally made their way to tertiary education institutions. Different from their urban peers, most of them had one or more siblings in the family. Their costs of tuition and living would consume all, or more than, the family income. They paid approximately 4,500 yuan each year for tuition and housing. Their monthly expenditure on life necessities was around 200-300 yuan or less. There were only 2 exceptions: Student $\mathrm{H}$, who consumed more than 1,000 yuan each month and Student I, who spent approximately 20,000 yuan on tuition and other life necessities every year. In the year of 2005, the minimum life guarantee for residents in the provincial capital of Shijiazhuang City was 220 yuan, which serves as a reference to indicate the low life standard of the rural students. It can be envisioned that most of the rural students were considerably confined by their poor economic condition and most of their routines are limited to simply meals and study.

The students are generally required to reside in student dormitories, with 4 to 8 persons sharing a room. Since cooking is basically impermissible in the dormitory, students normally dine in school canteens, where meals are offered at a less expensive price than at commercial restaurants. As the most frequent contacts occurred in the dormitory, it was natural that the interviewees paid much attention to daily details, such as life necessities, meals, consumption standard, which often symbolized a student's identity.

\section{Higher Extreme Versus Lower Extreme: Different Responses to Poverty}

The first comparison is made between students at the lower and higher extreme respectively to interpret the contradiction: At the lower extreme, the students were relatively poor, but tended to experience less psychological pressure, while it was the opposite at the higher extreme, where students were relatively well provided for.

Low extreme: village on the campus

Extract 1. Actually whether it is stringent or not depends on your psychology. (... ) I feel 200 yuan is acceptable. (Student A)

Extract 2. 200 yuan per month. Passable, that means, you cannot eat as you please, but you don't have to be too hard on yourself. (Student B)

Extract 3. (Do you feel your university life is very hard?) Do not find it very hard. It is OK. And I did not draw too much from my family savings. (Student G, state scholarship winner)

Student A, by referring to "psychology," in effect set the life standard at a relatively low level and readily accepted the status quo. This attitude might be related to a student's earlier experience in his or her rural homes. But it might be more related to the life standard of the schoolmates that constituted part of the daily life. A student canteen was not likely to serve very expensive meals. Yet, most rural students had to impose restriction on themselves so that "you cannot eat as you please" (Student B). Meanwhile, "you don't have to be too hard on yourself" (Student B) indicates a psychology of contentment. Obviously, they knew that there were students who depended on an even smaller budget.

The families of Student A, B and G did not purely depend on farming or other manual work, and the costs of tuition and living were tolerable, or within the financial capacity of their families. Their universities charged relatively low tuition; they studied in cities of relatively low consumption standards; and they were in contrast to students who had more financial 
PROBLEMS

OF EDUCATION

IN THE $21^{\text {st }}$ CENTURY

Volume 40, 2012

difficulties. If they had excellent grades, they could earn scholarship and further lessen their family burden. Thus they would find that university life was "OK" (Student G).

Most students were aware of urban-rural differences, especially when urban students' monthly expenditure nearly doubled that of rural students (Student C). The following extracts illustrate how rural students reflected on their urban peers:

Extract 4. [Urban students] indeed have a sense of superiority when they are together with us. (... ) I do not admire them. (Student E)

Extract 5. (Whether there is pressure in communication with urban students :) No pressure. I am not under pressure living here, because, I do not mean... mmm... sometimes I envy them, for they are better off financially. But on my part, I do not envy them. (Student F)

The attitude that they did not "envy" or "admire" their urban peers (Student E and F) was common among rural students at the lower extreme. Why did they appear indifferent to the obviously advantaged position of their urban peers, then?

Extract 6. (More rural students win scholarship :) [Urban students] seem to have put less effort on study than rural students do. (Student $\mathrm{C}$, state scholarship winner)

Extract 7. (Do you find that rural students feel more or less inferior?) In::fe::rior::? (drawn out) Inferior, of course, in certain aspects, say, in comparison with [urban students], that is, the urban students are very versatile, (... ) for example, they sing and dance and participate in collective activities. (... ) (Are there rural students who want to overtake them and inwardly make effort in this aspect?) In fact, as an innermost thought, yes. (... ) I used to have that thought. Why was I so lagged behind [in study]? (... ) I must push forward, I must make effort [in study]. (... ) (Whether it is financial pressure that makes rural students less active?) Maybe this is one factor. I find that my classmates are from very poor families. In general, those from poor families tend to have greater motivation and are very hardworking. Maybe this is the reason. I think we are all very excellent in study. (Student B)

Extract 8. As far as I see it, urban people, especially nowadays children, have no more merit than us. (... ) After all since childhood, they are the only child of their families, living in the city, which is simply a nest of abundance and ease. (... ) (Any special talents in urban students?) Special talents... in some aspects they do have more extensive knowledge than us, say, in playing games. Some of them know everything about playing computer games. (... ) (Do they read more books than you?) Reading books... also... varies from person to person. Some people read more books. They, urban people, like to read such books as Harry Potter. (Student E).

That urban students were "versatile" and had "extensive knowledge" (Student B and E) was more or less a consensus among rural students. At the lower extreme, however, these advantages were not much admired. Rural students deemed their experience in the countryside a source of their merits, attaching importance to their capacity to endure hardship and their excellence in study. This could be seen from the case of Student B, who redundantly emphasized school grades and associated this merit to poor family background. 
Admittedly, at the lower extreme, more rural students win scholarship, from which they take pride. But multiple factors work together to accomplish this. First, rural students make up the major bulk of the lower extreme. Second, rural students who finally made their way to university are the rare ones among their rural peers. Third, many urban students tend to have more extracurricular interests and "put less effort on study" (Student C). Since basic education, rural students are mostly focused on subjects that are included in university entrance examination. Some schools cancel such subjects as Physical Education, Music and Fine Arts. As a result, rural students have a narrower scope of knowledge and their outlooks are confined. They are unfamiliar with and consequently give less heed to the knowledge of human cultures, being unaware of how such knowledge might promote them in their future development.

Extract 9. Maybe I feel that students from the village, sometimes, several of them, do not accept the habits of those brought up in the city, thinking their way of life extravagant, that kind of life style, [rural students] very dislike it, it seems. (Student D, parentless)

In spite of the great disparity between the rich and the poor in China, most urban students at the lower extreme are from families of average income, or "belong to the salary-earner class" (Student C). It is not likely for most of them to have very high standard of consumption. Urban and rural students dine at the same canteens. Urban students may choose meals of better quality, while rural students may mainly depend on vegetables and cereal. Once rural students make up the great majority, urban students become exceptional. Especially to those from very poor families, the consumption standard of urban students would be considered "extravagant" (Student D).

More than taking poverty for granted, rural students might gain a sense of moral superiority from it. A life of simplicity is up to the standard of morality, while a wealthy life could be considered a corrosive factor. More important, this traditional value has been overstated in the main stream propaganda. This tends to confine the students to a stereotyped belief that poverty is not one's misfortune, rather, it makes one mature and perfect; when poverty is used as a spur for motivation, whoever works hard and has academic excellence will be eventually lift out of poverty. Consequently, many rural students found encouragement and standing from their academic excellence. They were not scared by the hardship at present, as long as a brilliant prospect awaited them in the future.

Extract 10. All [roommates] are from the village, are easy-going. And we have more communication, talking about each other's habits and customs and the like. (Student F)

Extract 11 . There were so many students who had the same or similar [poor] family background. On the contrary, these [poor] students tended to gather together and have relatively rare contacts with the small circle of the rich people. (Student C)

Apparently, rural students, greater in number, tend to dominate the discourse. When conversation concerns rural topics, urban students do not have much to say. This constitutes an important source of complacency for rural students, so that urban students' versatility and extensive knowledge have rarely stirred their poised psychology. There is, so to speak, a "wall of culture," which not only separates them from their urban schoolmates, but also provides them with a temporary psychological shelter against impact from the unfamiliar urban world. But this wall also functions as a segregation mechanism, so that they hardly have access to the rich resources that the city could offer, and they hardly realized this deprivation.

PROBLEMS

OF EDUCATION

IN THE $21^{\text {st }}$ CENTURY

Volume 40,2012 
PROBLEMS

OF EDUCATION

IN THE $21^{\text {st }}$ CENTURY Volume 40, 2012

In fact, the whole group of rural students at the lower extreme is shrouded in poverty. Financial aid supports a very small fraction of the students. In some cases, a school scholarship could be as symbolic as 100 yuan (Student F). It is common sense that poverty is an adverse factor in one's life. Yet, none of the above students mentioned the negative effect that poverty brought upon them as a whole. They did not even refer to money as a necessity for one's sustenance. As such, rural students at the lower extreme have more or less transplanted their rural society onto university campuses, so that they are still living in a small niche not quite far away from their home villages.

\section{Higher extreme: Impassible gap}

Extract 12. (Something deeply impressive :) When I just came here, I felt rather heavy. My tuition was, was... anyway was gathered with much difficulty. At that time and, everyday, I felt that I, anyway I was... different from others, under very heavy pressure. Anyway, when I was alone, I was always, very gloomy and, wanted to cry. (Student M)

Extract 13. Sometimes a meal alone could provide enough evidence. When we all brought meals to our dormitory to dine, you see, the money tho-those better off spent on one meal equalled to your cost for one day. So maybe the meals they bought were pro-probably better. Mmm... in this process, maybe, urban roommates, by comparison, could develop a sense of superiority, while rural roommates could more or less feel hurt. Although this would not lead to the kind, the kind of brush or conflict in speech, it was there all the time. At that time I, although we got along well, this kind of psychology per-persisted in me. So, sometimes I found it embarrassing to take my meal to my dormitory (chuckle). (Student L)

Extract 14. (Rural-urban differences on campus) Mmm... it is something that sometimes makes us more inferior. (...) Actually, I feel that one perceives these differences only when one is on the dark side. (Student K)

At the higher extreme, rural students are the minority. More financial aid is available to them. Living in metropolis, they should have a life of better quality than their peers do at the lower extreme. However, in immediate contacts with urban students, the differences between them and their urban schoolmates made them feel "heavy," "hurt," embarrassed and "inferior" (Student M, L, K). In the meantime, the sense of being hurt and inferior must have been mistaken more or less for a sin, for such feelings were attributed to "the dark side" of one's psychology (Student K). This would doubly burden the poor rural students. In spite of that, they spoke out their mind straightforwardly and admitted their embarrassment or "dark side." Being frank and honest, alone, was not enough. They must have been exposed to continuous and repeated hurts, on which they dwelt and reflected.

Extract 15. Now my parents are aged, can make little money. My father is now over 50 years old. Going out, anyway, normally, going out yet you find that you cannot do anything. (... ) And my mother, by herself, totally... totally helpless. So now they two... just put up with it, accept whatever they can make. (... ) You cannot expect too much. Everyone has his own way to survive. Those of lower status make do with a lower standard of life. 
Say, when I told [urban students] about my folks, (...) they just could not understand. Your monthly cost of living, they say, you earn so little money, that little money? How did you manage to get along, how to stay alive? (... ) They simply could not understand what I told them, just could not understand how rural people got along, how they survived. (Student J)

Extract 16. (Rural-urban brush?) Er... brush.... My dormitory was relatively a harmonious place, everyone on good terms. On other aspects, er, it, it is inevitable, definitely there was very big difference. (... ) (Urban-rural distance in culture and life?) Yes, right, right, right, it is very apparent, relatively apparent. (... ) Although they did not speak it out, but sometimes some people's expression, some expressed meanings, or bearings, as if telling you that you knew nothing, you rube (chuckle). (In case as such, did you sense disrespect for us rural students?) Mmm... yes, there are such elements in it. Some students did, of course not all students behaved like that. (Student L)

Income from farming is seriously insufficient, and off-farm jobs have become vital for many peasants. For those who are no longer fit for long-distance migration and heavy physical labour, the problem is a matter of survival more than a matter of living standards. The remark that one had to "accept whatever they can make" conveys a message of desperation.

At present, fully representational and accurate reports on the economic situation in rural areas are rare. Urban students, without personal experience, would find it very hard to understand the desperate poverty in rural areas. Difficulties in communication would estrange the young peers. Against a macro background in which the city dominates over the village, this estrangement may ultimately manifest as superiority on the part of urban students and inferiority on the part of rural students.

Extract 17. (Something impressive on campus :) A lot of students around me, they directly divided into two groups upon university entrance. (... ) Some [rural students] would change in character and began to contact some... but some students from badly-off background could not possibly go with others to dine, to sing. So, on the whole, they tend to be very restrained and indrawn. So, in such affairs as making speech in the class, including campaigning for class cadres, they are all... anyway, there exists this disadvantaged group on campus. (...) So, their developments are much hindered in some aspects.

As I told you just now, probably they just spontaneously divide into two groups. No matter how friendly they are to each other at the surface, there definitely exists that, that, that kind of invisible gap, the kind of gap that is impassable. (Student $\mathrm{H})$

The higher extreme, where more urban students gather, obviously offers more privileges than the lower extreme does, whether regarding the academic atmosphere on campus or the urban culture outside the campus. Rural students, however, tend to be excluded from these benefits. The reasons of this exclusion are various. Factors such as culture and personality are relevant, but what impressed the interviewees most was still poverty. Poverty denied them their psychological demands. They tended to be "very refrained" from social activities, which would erode their confidence and in turn "much hindered" their development in other aspects (Student $\mathrm{H})$. 
PROBLEMS

OF EDUCATION

IN THE $21^{\text {st }}$ CENTURY

Volume 40, 2012

\section{Higher extreme: A new perspective to look at poverty}

From the stage of basic education until higher education, most rural students have to drain their family finances. To relieve pressure, many rural students choose to take part-time jobs. Because of surplus in the labour force, work opportunity and income are very limited. Invariably, the experience of making money is filled with hardship, while the attitudes of students at different extremes may vary, as is shown below:

Extract 18. (Impression of the university's host city :) People [in this city] lead a life of ease. (... ) Any way, I do not enjoy stay in this city. (... ) (Do you still remember how you felt the first time you got paid for a part-time job?) Yes, I do. (Can you tell me?) Ai (sighing)... it is, ac-actually nothing much. Only, only shed some tears... (... ) Ai, this, this is, unfair. (Student M, at the higher extreme)

Extract 19. (First part-time job :) Very exhausting and much workload. In the end, the payment was very small, which they nearly denied us. (... ) Almost started a quarrel. We insisted on our demand. After all we put in effort and it was our first time. We were so ill used, very unhappy, very uncomfortable. (Student A, at the lower extreme)

Both students recalled hardship, but Student A at the lower extreme focused on details that were "very unhappy, very uncomfortable," while Student $M$ at the higher extreme, being more directly exposed to the "life of ease" in the big city, arrived at a more general conclusion that it was "unfair," pointing to social injustice.

Extract 20. "Tough life spurs you while soft life spoils you (classical proverb)." This "tough life," I do not prefer to interpret it as having a poor family background. Even if you are born in affluence, you might as well "get prepared for danger in times of safety (classical proverb)." With such an attitude, you may very well make use of the privileged condition that is denied to your peers and enhance yourself in all aspects. (Student L)

Extract 21. I used to believe that most of those who got excellent grades were from poor families, while those from affluent families tended to have relatively poor academic performance. But in senior high school, my belief was thoroughly subverted. In senior high school, I found that, in fact, the better the family condition, the better the student's performance and the greater his capacity to cope with practical affairs. (Student I, from Southern China)

Students L and I talked about a phenomenon which students at the lower extreme neglected: An advantaged socio-economic position, rather than a corrupting factor, is favourable for one's development. Once arriving at the higher extreme, these rural students were confronted with a new situation in which their urban peers obviously had more merits such as better school performance and greater capability to cope with practical affairs (Student I). This would upset their established stereotypes, evoke their reflection and restore them to the common sense that poverty is, after all, not a blessing.

In contrast, Students at the lower extreme appeared less alert to the harmful effect of an adverse background: 
Extract 22. (Why do you think there are so few urban students in your class?) Why there are so few urban students? For one thing, for one thing, this school is not very good, not famous; for another, it is... mmm... mmm? I don't know (laugh). (Student F, at lower extreme)

Admittedly, school grades are not necessarily related to family economic status. However, on elite campuses, rural students are a disproportionately small fraction, a hard evidence that adverse life does affect rural students negatively. Diligence, a merit in which rural students take such great pride, has not in the least altered the rural-urban student distribution in the higher education system. None of the interviewees at the lower extreme inquired why there were so many rural students in their classes and where their urban peers had gone. Nor did they question that while most of them were so excellent and hard working, why they were accumulated on the lower extreme.

On the other hand, it seems that only in the on-campus "village" is "psychology" capable of overpowering poverty. To some rural students at the higher extreme, the rural-urban gap just emerged "certainly," "directly," and "spontaneously," and the gap was "impassable," "inevitable," "definite," and "apparent" (Student H and L). Thoughts as such could not be triggered by accidental emotional impacts, but were the rewards of reflection. Further on, they saw hard experience no longer just as private affairs or affairs between peers. Such vocabulary as "disadvantaged group" (Student H) and "unfair" (Student M) indicate that these rural students were capable of making a departure from their individual experience to generalize to social groups.

\section{High Economic Standard versus Low Economic Standard: Same Poverty}

The following comparison is made between the interviewees who had "high economic standard" and "low economic standard" respectively, with the intention to explore if the variation in their economic conditions makes difference in them.

\section{Lower extreme: High university tuition versus limited student revenues}

Extract 23. (The cost of higher education :) Not so much as pressure, but my family is not so affluent as to take it easy. Anyway, family fund is hard earned. The economic condition being just so-so, the funding for study is not a problem, but not much surplus. (Student B, family income not purely from farming and manual work)

Extract 24. (Financial pressure :) Quite big, there is pressure. (... ) My family is just an average one. (... ) Because villagers do not have many sources of income, totally depending on my parents' toils. Money is hard earned. (... ) I spend 7000-8000 yuan a year, including tuition and cost of living. (You consumed all the family income). (... )Yes. It is common in the village. (Student $\mathrm{E}$, family income purely from farming)

Universities at the lower extreme enroll a high proportion of poor students and at the same time are insufficiently funded. It is therefore difficult for such institutions to provide aid to sufficiently cover poor students. For those who are not excellent in stdudy and whose families are not in extreme poverty, the availability of scholarship is scarce and the intensely contested need-based aids are inaccessible. These students, who are primarily dependent on family funds, have become the major victims of high tuition. Even Student B, who estimated education cost 
PROBLEMS

OF EDUCATION

IN THE $21^{\text {st }}$ CENTURY Volume 40, 2012

as tolerable, was guilty that the expenditure eroded considerably into family economy. Many among the rural students at the lower extreme are left in such embarrassment.

Extract 25. (Something impressive on campus :) Found it rather unfair, any way rather angry at that time. It has been in my mind for years. (... ) Maybe [we roommates] were relatively open-minded about cost on meals and ate a bit better. After all we were studying, afraid of damaging our health. (... ) [Students in other dormitories] all criticized that we spent money too casually, etc, etc. In fact, we just ate slightly better than they did. They only ate wheat bread and salted vegetables, while we sometimes ate eggs and fried vegetables and the like. (... ) As a result, in the first semester, five out of six in our dormitory were selected as poor students, while, later, there was none (laugh). (... ) (Poor students need to be selected?) There were too many who applied for needbased subsidy in our class. Our class was better, did not ask the poor students to present family conditions. Many schools asked students to stand on the classroom platform and read their applications, shedding much tears. (Student $\mathrm{G}$, state scholarship winnder)

With very limited funds, students who can get aids are bound to be very few. In Student G's class, for example, only 2 out of more than 30 students got state scholarship of 4000 yuan in 2007, a year that witnessed a great increase in state allocation. Earlier, in the case of Student C, only 2 or 3 students got state scholarship in a faculty of 6 classes. Since students from poor families are favourably considered in scholarship and other subsidy grants, a unique "poor students selection," or public appraisal to decide who deserved subsidies, is developed. When it is difficult to obtain accurate data about rural family economic details from authentic institutions, slight differences in students' daily life may become decisive in the public appraisal. When an applicant could be considered ineligible only because the diet included an egg or fried vegetables, it was obviously a case of exaggeration. To most rural students, financial aids are very important, since many of them are at a critical point: With a slight increase in financial help they can fulfil their study task; with a slight increase in financial burden and they suffer a greatly deteriorated life or even fail in their academic endeavour. It was only natural that Student G took the competition for subsidy very seriously and felt "rather unfair" and "rather angry."

Obviously, with very limited funds, it is impossible for all poor students to get relief, even if "poor student selection" was abolished. The indignation against the dispute at hand, i.e., the criticism against "poor student selection," could have aimed at a higher level, at the problematic system and further led to such questions as why rural students were almost unanimously poor, and why so many poor students had to contest for so little money and suffer the humiliation of "poverty presentation."

\section{Higher extreme: Debtor mentality and subdued attitude}

Extract 26. (Something impressive on campus :) My class had team spirit, very good. Like, say, my family was very poor, they, most of them could understand. And in all aspects, like scholarship application, they gave priority to me. (... ) I felt quite grateful to them. At first I felt they looked down upon people, disdained me. It turned out that it was not the case. All were very nice, much concerned about me. (Student J) 
Extract 27. (Something impressive on campus :) I feel that I am very lucky, lucky of me to be in this school. (... ) I feel that my classmates are very helpful to me, very supportive to me. Mmm, feel that I have gained much in this aspect. For example, work-study programs, state need-based subsidy and the like. (... ) And there is also state student loan, thanks to it, although the application procedure is very complex. ${ }^{4}$ (Student $\mathrm{K}$ )

Research shows that most rural students at the higher extreme can get various types of financial aids in such forms as scholarship, need-based subsidy, student loan, work-study programs, etc. These aids come either as government allocation or bank loans. However, Student $\mathrm{J}$ and $\mathrm{K}$ felt grateful to their classmates. As it was revealed above, rural students at the higher extreme tended to be sensitive to the rich-poor disparity among students. However, when others did them substantial favours, such as priority in financial aids grant, something intangible like "disdain" (Student J) tended to be ignored. Such gratitude did not seem to result from friendship between equals, but could be interpreted as a response to a favour. Meanwhile, a very practical problem can be illuminated: If most of the students were poor, like at the lower extreme, rivalry for financial aid would become unavoidable and the atmosphere would become unfriendly

Extract 28. (Something impressive on campus :) After all, my family condition was thus, so it was natural that in daily expenditure you had this kind of psychology: To spend as little as possible. (... ) Every time, after vacation, when new semester began, (...) I would take as little money as possible. After all, the family was burdened with costs of farming production. So, every time before leaving home, I felt gloomy. (Student L, scholarship winner)

In the case of Student L, higher education took a heavy toll: A younger sibling dropped out of school to save money. At the level of basic education, many rural students' family economy was already overdrawn and on the verge of bankruptcy. At the level of tertiary education, financial aids granted to them are not so significant as to bring about fundamental improvement. As a result, many rural students at the higher extreme, as much as those at the lower extreme, are heavily in debt to their families.

The following extract is from Student $\mathrm{H}$ (from a civil servant/peasant family in the North), the only student who studied within the geographical boundary of Hebei Province and consumed more than 1000 yuan each month:

Extract 29. (Fund :) It is OK in my case. I fully depended on my family. Everything, including cost of living, comes from my family, because my family is relatively well off.

(As a rural student, you have been very successful breaking urban exclusion.) The reason lies in this: The factor of economy underlies many phenomena. As I told you just now, I spent 60 thousand yuan during my 4 years in university. This may not be very much for some urban students, but it is not that easy to accumulate this sum from the village.

It was a subdued attitude on [the rural students'] part, as well as their hard-working character, that pulled them through in their endeavour (...). (Student $\mathrm{H}$ )

To Student $\mathrm{H}$, the price for higher education was great. However, this expense could not be spared, for money functioned as stepping-stone, without which the mainstream student community would be inaccessible. When approaching the entrance to university with finances 
PROBLEMS

OF EDUCATION

IN THE $21^{\text {st }}$ CENTURY

Volume 40,2012

that were luxurious for peasants, but not abundant for life in metropolises, Student $\mathrm{H}$ was in great contrast to the urban peers who had a whole system of privilege, including good basic education, cultural familiarity and a curriculum that favoured their background. Although declaring no financial pressure, Student $\mathrm{H}$ could not possibly be exempted from it. To span the urban-rural gap, money may be the most straightforward approach, although the gap may have been created by many other factors including information and culture as well as economy. However, to most rural students, whether they depend on family funds or scholarship, this route is blocked. A case brought in for contrast is Student I, who studied in a southern metropolis, where social disparity is more salient. Student I claimed to be under financial pressure, in spite that the consumption standard is similar to that of Student H. A recent survey made in a southern metropolis reveals that the monthly expense of some rich students could be as high as 8,000 yuan. ${ }^{5}$ Had Student $\mathrm{H}$ studied in a southern metropolis, the cost of higher education would have become a very heavy burden.

Many rural families have to reduce their standard of living or get into debt to support their children. As a result, many rural students have a guilty conscience. "Taking so much money at once from family saving, I felt very sorry" (Student B, at lower extreme, who found higher education cost bearable). "After all a grown-up now, anyway find it embarrassing to ask for money" (Student M, at higher extreme, who found higher education cost unbearable). On the whole, rural students, whatever their category, are invariably burdened under the heavy cost of higher education. The elites of the elites among Chinese rural youths, ${ }^{6}$ though physically present in the metropolis, still remain in the shadow of their impoverished rural homes. As such, the division that intersects across the four groups of rural students in Table 1 and 2 is getting blurred, while the border that separates them from the city has become more distinct.

\section{The Higher Extreme versus the Lower Extreme: Illusion or Marginalization}

The following comparison is made between students at the lower and higher extreme respectively, in order to uncover how rural students' standing in the higher education hierarchy may influence their future orientation. This touches upon the aspects of upgrading academic qualification, employment, etc. Economy, though, remains a visible theme in this section.

\section{Lower extreme: Under illusion}

Extract 30. I am also looking for a job, for graduation is nearing.... Not easy, not at all. (... ) [In finding a job] I guess the most important factor is still personal factor, because even if you enter a company through social relations, your merits still need to be verified. Your ability can serve as the index of your strength. (... ) (What, if we only look at the initial recruitment?) Maybe it equally depends on both, on social relations and on yourself as well. (Do you have relations in Shijiazhuang (the capital of Hebei Province)?) No, not influential relations. (Do you feel you have a chance in Shijiazhuang?) Er... I guess chance... chance, well, only for positions that are not so good. (Student A)

Extract 31. After all there are too many university students now. It is difficult to find a job. Sure there is pressure. (... ) (Those who graduated earlier and are still without job, what are they doing now?) Some are running small shops, selling ice cream near school, sell ice cream; some sell clothing, rent a shop and sell clothing. Engaged in various kinds of things. ${ }^{7}$ (Are they all from the village?) Yes, from the village, all from the village. (Do you think it fair?) It is quite fair as I deem it. In the present day society, capable persons get on. (... ) When 
you cannot find a job, you cannot blame it on others. You can only say that you have no ability. (Student E)

In their childhood, most of the rural students showed outstanding performance in their study among their peers. It is justifiable that they are very proud. However, their inadequate educational formation has restricted the structure of their thoughts and knowledge, so that many of them are clever in school examinations only. Universities and colleges at the lower extreme indiscriminately duplicate the stereotypes that adhere to unenlightened teaching methods. As a result, school products tend to be identical. Outside the campuses, Chinese economic development heavily depends on labour intensive industry, which mostly recruits workers with low educational attainment levels, giving limited room for university and college graduates. In this situation, the major factors that affect employment obviously go beyond personal ability. In fact, rural students at the lower extreme are challenged from both sides: On the one hand are students at the higher extreme, who bask in the halo of their prestigious schools; on the other hand are urban students, who have more social resources and shelters in the city. Student A and $\mathrm{E}$, however, failed to see the factors underlying the employment crisis, for university education did not deepen their insight into the overall system.

\section{Higher extreme: Victims of Marginalisation}

Extract 32. As far as I am concerned, the main purpose of leaving home is to find a job. (... ) They are urban children and seek help from their parents, while we can only rely on ourselves. (Thinking about going up to graduate study?) Certainly did. Mmm, had better make money first and support myself. (... ) Family has provided me for so many years, anyway, almost all the money is used up to support me through. In the end, if I go home and continue to rely on my family, it's really unacceptable. Too shameful to go home. (Student K)

Extract 33. I feel that anyway we are different from people here. After all, we want to come out [of the village] and it is just for this aim that we have taken all the efforts. Unlike [the urban students], they have always been here and do not have to worry about some future plans. (Student M)

Extract 34. For graduate study, I applied to X University (a subclass-1 university). (... ) We three persons were candidates for the final interview. Three persons and the other two graduated from X university. The supervisors used to teach them and they were in the same faculty. Then I was eliminated and was transferred to this [subclass-2 university]. (... ) Anyway this is very common. Because at that time I was told.... So, now many people ask me why don't you apply for a position of civil servant. Because, considering many factors, you cannot just rely on your scores and take it for granted that you can make it.

(The experience of study :) If I could choose, I would rather be exempted from such experience. Too heavy. (... ) Had to persevere. Persevered not because of strong will, but because there was no other choice. (Student $\mathrm{H}$ )

The following extract is from Student C, who had undergraduate education at the lower extreme in Hebei Province, but had graduate education in a southern metropolis. Once located at the higher extreme, where the students' socio-economic background differed sharply, Student $\mathrm{C}$ became alert to the disadvantaged position as a rural youth: 


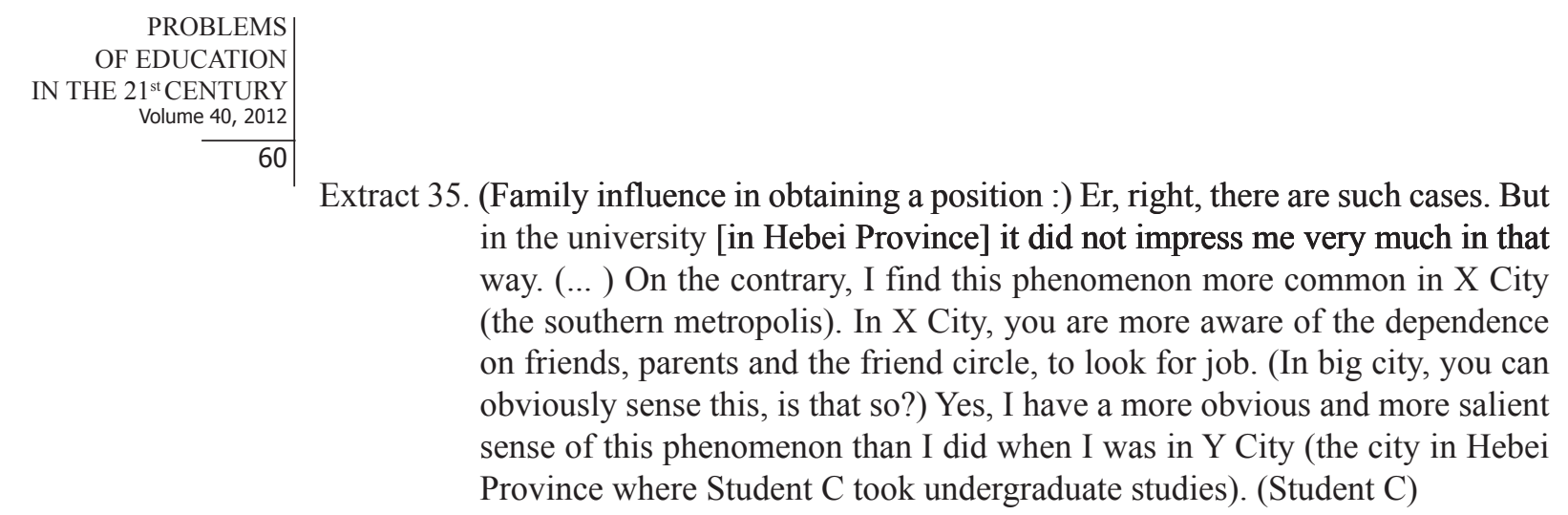

Comparatively, rural students at the higher extreme, though academically more competitive, seemed less confident. And they were more aware of the fact that, unlike urban students, they could not get help from social relations when looking for a job. They did not equate school grades and individual ability with good work position. However, their practical attitude was a "subdued attitude" (Student $\mathrm{H}$ ), or concession to humiliation.

To some extent, students' perceptions of reality seem to vary with how much they approach the metropolis, where social stratification is salient: Student I, at the stage of senior high school, became alert to the correlation between school grades and socio economic status; Student $\mathrm{H}$ did so upon entering university; Student $\mathrm{C}$ found social relations counted much when arriving in a big metropolis; Student A and E, who were away from big cities, were convinced that individual ability was decisive. Students' future choices and the consequences of their choices could be influenced by how near their judgments about themselves and the society come to reality.

\section{Dilemma}

Extract 36. This was my first choice, directly applied to this school. Feel it safer in this way. Application for better schools might fail. Had better be safe. (Student D)

Extract 37. One goal was to be admitted to a school. (... ) In fact I was very blind, so to speak. (In this blindness, there is one very important theme, that is, to leave the village as far as possible, right?) Right, right, right, find a school in the first place. (... ) (Had you a very affluent family condition, would you give priority to your interests?) Er... as to interests, because at the bottom level, in general, I do not feel that enough attention is given to cultivating interests. As to the students' own interests... they hardly know what they will do in the future, or where their interests lie. (Student C)

Extract 38. This [better-off family condition] and the fact that my parents had no regret at breaking away from the soil provides financial and psychological support to a rural youth who chose to go in for higher education. (Student $\mathrm{H}$ )

Most rural students who study hard with the purpose of leaving the village are in fact more urged by the plight at present than inspired by their studies or attracted by some grandiose promise in the future. Higher education paves a route to the city. However, peasants, living in the closed rural environment, are unfamiliar with school affairs. Teaching staff in rural schools tends to be poorly informed about university curriculum. As a result, most rural students are more or less blind about choices of schools and subjects. Nevertheless, behind this blindness lies the solitary goal: to uproot from the soil and therefore to be admitted to a school at any 
rate. In this case, they would choose schools and majors of less prestige and less competition in relation to their urban peers. In so doing, they choose a position that is disadvantageous for their future upgrading and employment.

Confronted with the employment crisis, many rural students falter between two choices: academic qualification upgrading or employment. On the one hand, they look forward to financial self-reliance and then reward to their families. On the other hand, finding themselves in a disadvantaged position, they endeavour to upgrade their academic qualifications as a way of increasing their competitive capacity. This puts them into a circle of dilemma: They must have good qualification to get satisfactory jobs; they must have money to upgrade qualification; and they must have satisfactory jobs to make money. Urban students have advantaged social relations to buffer the impact of employment crisis to some extent. In contrast, rural students, once back to their home villages, would lose their foothold in the city and have even less chance to find jobs. What is more, they will find that their parents are too worn out to continue manual labour. The remark that it was "too shameful to go home" (Student K) reflects a typical psychology that hangs heavily over many rural students.

Rural students at the lower extreme are in the most unfavorable position: With limited financial aids, they are more likely to sink their families in desperate poverty. "The village on campus" may temporarily buffer against the impact from the city, it may also slow down their active response to the external changes. Once they are precipitated into the employment crisis, they may have to pay a very heavy toll, and may even think that they are trapped in a snare of their own making. An incident happened that may illustrate the findings in this research: Liu Wei, a rural student who became hopeless about her employment prospect, chose suicide in February 2009, only half a year before graduation. Liu Wei was a typical poor rural student at the lower extreme: Although she was excellent in study and once granted state scholarship, her family was in debt and her younger brother discontinued education to save fund. According to the newspaper report, Liu Wei used to be a "very confident and very strong girl." She would rather "be thankful to poverty" than complain, for poverty was supposed to make her "strong and mature." In the long run, poverty brought her under pressure: Family being heavily in debt, while she, "a grand university student," continued to "draw on the toil" of her parents without the hope of finding a job -- "How shameful!" To overcome frustration, she relied on "psychology": "The key of healthy psychology is yourself.... Study harder, get equipped, perfect yourself, and the situation will improve." Nevertheless, "psychology" failed to save her life (Jingdong, 2009).

Liu Wei's diary overlaps with the extracts cited above, not by accident. The data and analysis reveal that many rural students came to the entrance of university with confidence. They have been financially burdened and morally in debt for years. Disillusionment about the future may become the last straw that breaks a camel's back. The way that Liu Wei chose to rid her agony is accidental, while her experience is not unique.

\section{Discussion}

Bourdieu's concept of the field and habitus (1992) could shed light on the phenomenon that the rural students located respectively at the high and low extreme give different responses to poverty. The Chinese higher education institutions, apart from being a university field, is a locus where the rural field and urban field overlap. The higher extreme of the locus tends to be dominated by urban students, while the lower extreme tends to be dominated by the rural students. This is unique of the Chinese higher education system that reflects the urban-rural segregation system. 
PROBLEMS

OF EDUCATION

IN THE $21^{\text {st }}$ CENTURY

Volume 40, 2012

62

At the lower extreme, the rural students tend to be confined in a closed mini rural society duplicated on the campuses. In the financially harsh condition, the rural students manage to maintain a poised psychology. One of the reasons may be that, basically, they are still living in the old field where they stick to their old habitus. Thus is created a harmony between them and the environment, so that they do not feel repressed and marginalized. This confirms the observation of Bourdieu that habitus is "at home" in the field it inhabits (Bourdieu \& Wacquant, 1992, p. 128).

Nevertheless, the rural students may have to pay a heavy price for feeling at home. According to the observation of Bourdieu and Passeron (1990), school authority tends to create the illusion that conceals the correlation between the symbolic violence exerted by an educational system and the existing power relations. With respect to working-class children, "the cultural arbitrary" of their class may leave "less room for moral indignation at forms of repression which anticipate the sanctions most probable" for them. They tend to be more "rigorously selected" and have better school performance. Yet, the social order may refuse to call them to "over-ambitious destinies." The educational system may even disguise "chances of entry" as "chances of success," so that they might become the victims of "deferred elimination" without realizing it (p. 65, 16, 72-80, 207, 159). Lindner (2006) has also observed that underlings may take the pain that came with their lowliness as "honorable medicine" (p. 165). Accordingly, Chinese rural students, because of their previous harsh life condition which has structured the rural habitus, as well as the main stream propaganda that overstates the effect of "honorable medicine", may let go obvious social injustice undetected. They tend to neglect the fact that they are rewarded by better academic record largely because the educational system has imposed a much more rigorous selection on them than on their urban peers. They may even sacrifice their academic ambition for their ultimate goal: to break away from the village. More serious, they might become the victims of a deferred elimination and ultimately excluded from the arena after, rather than before, they have exhausted all their resources in exchange for a higher education qualification. It seems that their illusion about higher education persists, even when the system functions as an instrument to drain financial resources from them, yet fails to sufficiently convert their merits, such as diligence and perseverance, into deep insight and high competence on the employment market. In a nutshell, they fail to see the correlation between the higher education system and the existing relation powers.

On the other hand, the rural students at the higher extreme make up a minority on the campus. Apparently, their life differs from that of their urban peers in content and quality. Fundamentally, they have entered a new field to which their old habitus stands in their way. It may be frustrating to find one's habitus under challenge, and it would take much effort to readapt one's old habitus, which is durable and transposable, to a new field. But that, alone, does not necessarily lead to injustice. According to Bourdieu (1992), the position of an agent in a certain filed may be defined by two factors: "the volume and structure of his capital" and his "objective relation to other positions" (p. 97, 99). In fact, in the macro hierarchical structure of urban-rural segregation, the existing power relations have assigned the village and the city to unequal status. The urban field rejects the rural habitus, not only as heterogeneous, but also as unworthy. As a result, the rural students would find themselves marginalized in the new field and proletarianized with respect to social and cultural capital, as well as economic capital.

As Lindner (2006) points out, when people have more opportunities to compare themselves with others, they are likely to detect more existing inequalities. When they are shown the benefits that are entitled to other equal human beings, yet at the same time deprived of those very benefits, ill feelings such as feelings of humiliation must be expected to increase. There have been situations throughout history in which "pain was valued on its own account, not just as a regrettable yet necessary side effect." Only after making "long mental and emotional journeys from honor humiliation to human rights steered dignity humiliation" is it possible for 
individuals to define themselves as victims (p. 42, 43, 18, 29). The rural students at the higher extreme, like their counterpart at the lower extreme, used to take plight as honorable medicine.

Arriving at big cities, they are at once directly exposed to the sharp contrast between the urban and rural areas, a condition under which deprivation cannot so easily go undetected. They tend to be sober in making judgments about themselves and the society, because they are aware of the humiliation that they are deprived of the very benefits entitle to their urban peers, and that the gap between them and the city is impassible. The halo of famous universities that crowns them and the various financial aids that are granted to them cannot make up for the humiliation that they have suffered as an inferior social group.

\section{Conclusions}

Rural China and urban China belong to two separate spaces, or even two different eras. Other societies that apply welfare measures greatly reduce disparities in life necessities between different social strata. For Chinese students, in contrast, daily details such as meals serve as indexes of "the rich" and "the poor," and, in turn, as indexes of "the urban" and "the rural." Close contact of the rural students with their urban peers may intensify their sense of affiliation to the village, and they may oppose the village to the city. Given the seriously imbalanced urban-rural resource distribution, the higher education system will eventually assign urban and rural graduates to unequal social positions. Especially when exposed to employment crisis, the rural students have the danger of being left in desperation to repeat the tragedies that are bred in poverty. More fundamentally, via the durable and transposable habitus, the ruralurban segregation system, an external government coercion, will have become internalised into people's mentality. Thus, the Chinese universities and colleges play a critical role in the reproduction of the urban-rural segregation system.

\section{Acknowledgements}

My warmest thanks go to Mr. Magnus Haavelsrud of Norwegian University of Science and Technology (NTNU), who supervises my research and gives timely help and guidance, and to Mr. Tony Jenkins, who very kindly edited my language.

\section{References}

Baiqian (2010). 白浅 中国历年大学毕业生人数统计 [Annual Statistics of university graduates in China]. Retrieved19/05/2010, fromhttp://www.cnwnews.com/html/chuangye/cn_zxbb/20100519/218847. html.

Bourdieu, P., \& Passeron, J. C. (1990). Reproduction in Education, Society and Culture. London: SAGE.

Bourdieu, P., \& Wacquant, L., (1992). Invitation to Reflexive Sociology. UK: Policy Press.

Dong, J. (2004). A policy study of the position of rural students in the transition from elite to mass higher education in China. Thesis (MA). University of Oslo. Retrieved from http://www.duo.uio.no/publ/ pfi/2004/112875/jingyi-dong-final-thesis.pdf.

Fu, J., \& Wang, C. (2010). 付君萍 王岑予 大学生最高消费一月八千元 [University students' monthly expense can be as high as 8,000 yuan]. Retrieved 2/06/2010, from http://txs.youth.cn/dxzx/ tp/201007/t20100702_1276085.htm.

Giske, T., \& Artinian, B. (2007). A personal experience of working with classical grounded theory: From beginner to experienced grounded theorist. International Journal of Qualitative Methods, 6 (4), 67-80.

Glaser, B. G., \& Strauss, A. L., (1999). The Discovery of Grounded Theory. USA: Aldine Transaction. 
PROBLEMS

OF EDUCATION

IN THE $21^{\text {st }}$ CENTURY

Volume 40, 2012

Jingdong (2009, February 26). 静冬 女大学生不堪就业压力自杀 留下10万字日记 [Stressed out by unemployment, a female university student committed suicide leaving behind a hundred thousand word diary]. Yanzhao Metropolis Daily. Retrieved from http://news.sina.com.cn/s/2009-0226/022217289030.shtml.

Jørgensen, M., \& L. J. Phillips (2002). Discourse Analysis as Theory and Method. London: SAGE Publications Ltd.

Kang, N. (2001). 康宁 论教育决策与制度创新 [On education policy making and innovation]. Retrieved 23/06/2006, from http://www.edu.cn/kuo_zhao_314/20060323/t20060323_25017.shtml.

Lindner, G. E. (2006). Making Enemies: Humiliation and International Conflicts. Westport, CT, London: Greenwood/Praeger Security International.

Liu, Y. (2003). 刘尧 农村知识贫困与农村高等教育 [Lack of education in the rural areas and higher education for the rural areas]. China Education and Research Network. Retrieved 15/01/2003, from http://www.edu.cn/20030115/3075978.shtml.

Potter, J., \& Wetherell, M. (2001). Unfolding discourse analysis. In M. Wetherell, S. Taylor, \& S. J. Yates (Eds.), Discourse Theory and Practice: a Reader (pp. 200-209). London: Sage.

Taylor, S. (2001). Locating and conducting discourse analytic research. In M. Wetherell, S. Taylor, \& S. J. Yates (Eds.), Discourse as Data: A Guide for Analysis (pp. 5-48). London: Sage.

Trow, M. (1973). Problems in the Rransition from Elite to Mass Higher Education. CA: Carnegie Commission on Higher Education.

Zhang, Y. (2003). 张玉林 分级办学制度下的教育资源分配与城乡教育差距 : 关于教育机会均等问 题的政治经济学探讨 [Education resource distribution and inequality in rural and urban education under an education policy of localization]. China Rural Survey, 1, 10-22. Retrieved from http:// www.cqvip.com/onlineread/onlineread.asp?ID=7452778.

(Endnotes)

1 In the urban-rural segregation system, most peasants are registered as permanent rural residents, a status that is passed down from parents to children. Peasants are excluded from many privileged professional fields, and many social welfare policies benefit permanent urban residents only. At the level of basic education, it is the rural local governments that provide the funding, often insufficiently, to peasants' children that are institutionally chained to their home villages.

2 Students graduated from Chinese universities and colleges in recent years: 2.12 million in 2003; 2.8 million in $2004 ; 3.38$ million in 2005; 4.13 million in 2006; 4.95 million in 2007; 5.59 million in 2008; 6.11 million in 2009; 6.31 million in 2010 (Baiqian, 2010).

3 Student $\mathrm{G}$ claimed to have financial pressure at one time, but claimed not having consumed much family funds at another, thus is included in both Group 1 and 2.

4 Student loan must be returned two years after graduation, even if the student could not find job.

5 A survey in 2010 in Guangzhou, a big southen city, reveals that students' monthly expenditure varies from less than 300 to about 8,000 yuan (Fu \& Wang, 2010).

6 Allotment of opportunities to enter famous universities are based on quota which heavily favors residents in metropolises. Take, for example, two top universities in China, Peking University/ Tsinghua University: In 2009, the two universities respectively enrolled 180/253 science students from the City of Beijing, but enrolled only 14/45 students from Hebei Province. In contrast, the required score for admission to the two universities was 653/653 for Beijing residents, but 677/680 for Hebei students (Information source: www.sina.com.cn).

7 “Small business" in urban areas used to sustain peasants or those without a "profession." Later, large population of laid-off industrial workers, and by now, university graduates, step in the arena, too.

Advised by Andris Broks, University of Latvia, Latvia

Received: January 11, 2012

Accepted: March 13, 2012 